\title{
La competencia textual y mediática en el aula de $\operatorname{ELE}^{1}$
}

\author{
MARTA UlLOA \\ Universidad de Kassel (Alemania) \\ BERND TESCH \\ Universidad de Kassel (Alemania)
}

\begin{abstract}
Resumen: La habilidad de comprender y producir textos es una de las competencias básicas en la sociedad de la información y de la comunicación (OECD, 2000). Sin embargo, el concepto texto ha evolucionado adquiriendo una versatilidad que rebasa la concepción tradicional de texto escrito. Para superar este desfase al que la competencia lectora o las destrezas en la comprensión y/o expresión oral no llegan, se propone el término competencia textual y mediática ${ }^{2}$. La finalidad de esta comunicación es reflexionar sobre la importancia de esta competencia y dotar al profesorado de herramientas en el tratamiento de la competencia textual. Para ello, presentaremos un modelo bidimensional de competencia textual y mediática: la que el alumnado debe adquirir y la competencia didáctica que el profesorado debe poseer.
\end{abstract}

Palabras clave: texto, competencia textual y mediática, elaboración de tareas

\begin{abstract}
The ability to understand and produce texts is one of the basic competences in the information and communication society (OECD, 2000). However, the concept text has evolved beyond the traditional conception of written text. In order to overcome this gap, a new competence, the textual and medial competence is proposed. The purpose of this communication is to reflect on the importance of this new competence and to provide the teaching staff with tools in the treatment of the textual competence in the classroom. For this we present a bidimensional model of textual and medial competence: the one that students must acquire and the didactic textual competence that teachers must have.
\end{abstract}

Keywords: text, textual and medial competence, task design

\footnotetext{
${ }^{1}$ El artículo se basa en los resultados del proyecto P37: «Complejidad y Competencia Textual», financiado desde el macroproyecto «Profesionalización del profesorado mediante el trabajo en red» (Professionalisierung durch Vernetzung, PRONET). La meta es proporcionar al profesorado herramientas didácticas (estrategias de comprensión, estructuración, planificación, simplificación y elaboración de tareas con textos) para potenciar la competencia textual en el alumnado. La lingüística se ocupa de la complejidad textual y, en didáctica, nos ocupamos de la competencia textual y mediática. El proyecto ha sido financiado, en el marco de la «Promoción de la calidad en la formación del profesorado» (Qualitätsoffensive Lehrerbildung) por el Gobierno federal y los Estados federados, con fondos del Ministerio Federal de Educación e Investigación de Alemania (Bundesministerium für Bildung und Forschung) bajo el número de concesión 01JA1505. La responsabilidad del contenido de esta publicación recae sobre los autores.

${ }^{2}$ En alemán, Text- und Medienkompetenz.
} 


\section{Introducción}

El papel de la lectura y la escritura en la sociedad ha ido evolucionando paralelamente a los cambios sociales, económicos y tecnológicos. El concepto de aprendizaje a lo largo de toda la vida ha transformado nuestras creencias sobre la competencia lectora así como las necesidades a las que esta debe hacer frente. Ya no se considera que la competencia lectora se adquiera únicamente durante los primeros años de escolarización sino que incluye una serie de conocimientos, habilidades y estrategias que las personas van construyendo con los años, según su experiencia, sus necesidades y mediante la interacción con otras personas y con las comunidades en las que participan (Portmann-Tselikas, 2005). Actualmente un gran número de nuestras comunicaciones son digitales y esto ha facilitado el cambio en la perspectiva receptor/emisor. Asistimos a una época en la que ya no somos meros consumidores/receptores o autores/emisores de textos sino que somos prosumidores, esto es, actores comunicacionales que producen tantos textos como reciben (Islas Carmona, 2008). Este cambio de actitud respecto al tratamiento de textos necesita de un giro educativo que prepare al alumnado y al profesorado a estas nuevas necesidades sociales.

Desde que el Marco de Común Europeo de Referencia para las Lenguas (de ahora en adelante, MCER) definió las competencias para la adquisición de lenguas extranjeras (Consejo de Europa, 2001) y el proyecto Definición y Selección de Competencias (de ahora en adelante, DeSeCo) implementó y operacionalizó en competencias clave los pilares o macrocompetencias sobre los cuales la educación del s. XXI debe sostenerse (OCDE, 2005) asistimos a un cambio en los curricula educativos, en la estructura de los manuales de enseñanza y en la práctica docente de lenguas extranjeras. El objetivo no es ya la acumulación de conocimientos declarativos sino el desarrollo de las posibilidades del alumnado mediante la aplicación, en contextos concretos, de habilidades para saber, saber hacer, saber vivir juntos y para saber ser (Delors, 1996). El proyecto DeSeCo apunta que el desarrollo de una competencia implica

[...] la movilización de destrezas prácticas y cognitivas, habilidades creativas y otros recursos psicosociales como actitudes, motivación y valores... [con el fin último de promover] la habilidad de los individuos de pensar por sí mismos como expresión de una madurez moral e intelectual, y de tomar responsabilidad por su aprendizaje y por sus acciones

$\operatorname{OECD}(2005: 8)$.

Se refiere a la promoción de un pensamiento reflexivo que permita a la persona asimilar y relacionar lo aprendido con su experiencia para poder tomar decisiones acerca de su modificación, adopción o desestimación. Este proceso implica un grado de desarrollo cognitivo entendido como el desarrollo de las funciones psicológicas superiores vigotskyanas (Vigotsky, 1989). Cullen (1996: 21) añade la necesidad de intencionalidad educativa ya que las competencias no se desarrollan por sí mismas sino que hay que aprenderlas para que funcionen como "sistemas abstractos de reglas, capaces de generar nuevos saberes».

La identificación de la competencia comunicativa en lengua (materna o extranjera) únicamente con las competencias comunicativas funcionales (comprensión y expresión escrita, expresión oral, comprensión (audio)visual, mediación y conocimiento lingüístico) 
no da cuenta de la complejidad de los procesos de aprendizaje en lenguas extranjeras (Burwitz-Melzer, 2007). En Alemania, en los últimos años ha habido un gran intercambio teórico, en el campo de la didáctica que ha dado como resultado la inclusión de una nueva competencia en la normativa educativa.

\section{Definición de la competencia textual y mediática}

El sistema educativo alemán, en su Conferencia Permanente de los Ministros de Educación y Asuntos Culturales (en alemán, Kultusministerkonferenz (de ahora en adelante, KMK), sistematizó la competencia comunicativa en las primeras lenguas extranjeras (inglés/francés) en varias subcompetencias. En su edición de 2012 incluyó junto a las competencias comunicativas funcionales (que incluyen las destrezas, la mediación y el conocimiento de la lengua), la competencia comunicativa intercultural, el saber aprender lenguas extranjeras, la conciencia lingüística y, por primera vez, la competencia textual y mediática. La competencia comunicativa en lengua extranjera se representa en la figura 1.

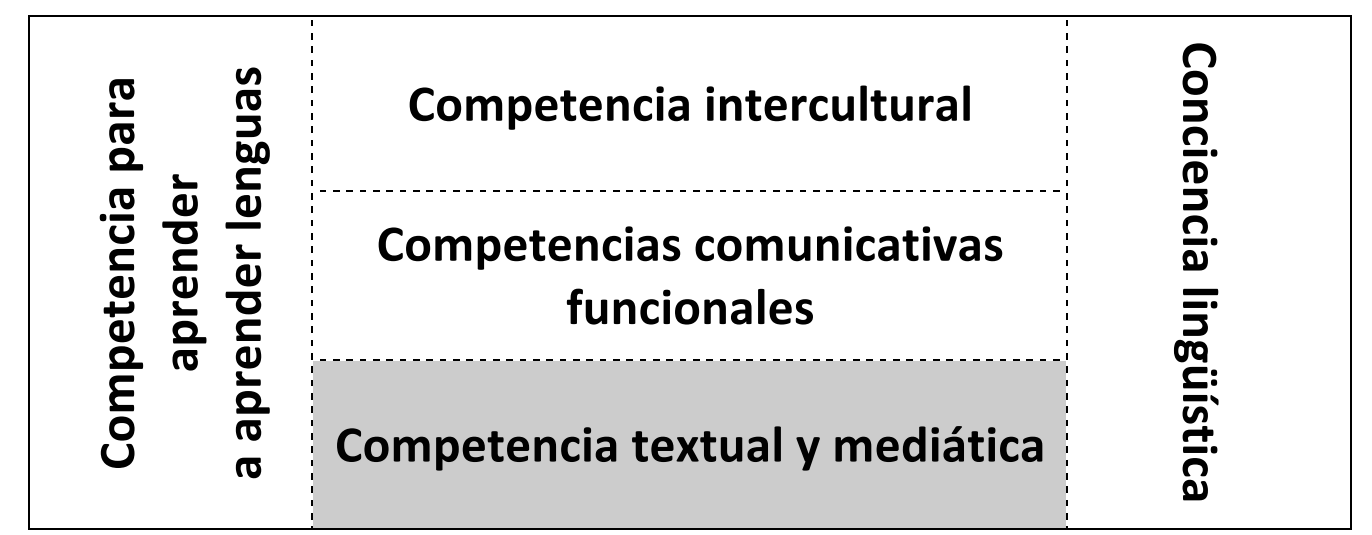

Figura 1. Subcompetencias de la competencia comunicativa en lengua extranjera (KMK, 2014: 12)

La competencia textual y mediática se presenta como una competencia integradora y estrechamente relacionada con las demás, pero con unas demandas específicas. Esta competencia implica el conocimiento declarativo, procedimental y actitudinal en cuanto a las condiciones en las que la información es codificada y procesada en los distintos tipos de textos, así como sus reglas y características lingüísticas específicas (Burwitz-Melzer y Caspari 2017: 58). Supera ampliamente la idea tradicional de competencia lectora como proceso de decodificación y comprensión literal y queda definida como la competencia que

[...] facilita la comprensión e interpretación de textos continuos y discontinuos, incluidos los audio(visuales), teniendo en cuenta sus relaciones y suposiciones. Engloba tanto la identificación de las características convencionalizadas y específicas de la cultura de los textos y medios, el uso de esas características en la propia producción, así como la reflexión del proceso individual de recepción y producción

$\operatorname{KMK}\left(2014\right.$, p.20). ${ }^{3}$

\footnotetext{
${ }^{3}$ La traducción es de los autores.
} 
La definición amplía, en primer lugar, el concepto de texto teniendo en cuenta su diversidad. Esta diversidad se integra por primera vez en las destrezas convencionales (leer, escribir y comprensión audiovisual) lo que permite un tratamiento más sofisticado de las mismas. Cuando escuchamos la palabra texto, la mayoría de nosotros imagina un producto escrito y elaborado con cierta formalidad, con unas cualidades más o menos estáticas y cuyo significado es unívoco e idéntico para todos los posibles lectores. Sin embargo, en un sentido amplio, el término texto se extiende a cualquier forma de producción de lenguaje, en cualquier formato (oral, escrito, audiovisual) y en cualquier medio de comunicación o soporte (Isenberg, 1976; KMK 2014: 20; MCER 2001: 95). Desde esta perspectiva las pancartas en las manifestaciones, las reuniones de vecinos, los justificantes de compra, las instrucciones de montaje, los anuncios en cualquier soporte y formato, los videoblogs, los mapas de metro, los del tiempo así como los poemas, artículos, libros, comics, etc. son textos. Sin embargo, no tratamos ni reaccionamos a todos esos textos de la misma manera. Algunos textos condicionan nuestro comportamiento (p. ej. la publicidad o el mapa del metro cuando tenemos que llegar a una parada determinada). Otros no van dirigidos a nosotros y los obviamos (López Ferrero y Martín Peris, 2013).

Los estándares educativos de esta competencia que define la KMK (2014: 20-21) aportan una nueva conceptualización sobre el tratamiento de textos y medios de comunicación en la enseñanza de lenguas. La competencia textual recurre a la comprensión global como requisito para cualquier procesamiento superior de todo tipo de textos e implica la habilidad para resumir, estructurar y analizar un texto. Esta comprensión global posibilita la interpretación, es decir, un análisis detallado de diferentes niveles (tipología textual, elementos estilísticos y retóricos, contenido, de la habilidad lingüística general, diseño y disposición...). El conocimiento previo sobre estos niveles es la base del análisis y como las distintas personas difieren en su conocimiento previo, el análisis resultante es necesariamente diferente. Es decir, cada persona crea su texto en un proceso personal de interpretación, asimilación o reflexión personal. Tras esta interpretación es posible realizar una valoración crítica del texto o del efecto que sus distintos elementos producen en el receptor. En los estándares alemanes, la empatía con los personajes constituye otro indicador de la competencia textual y mediática puesto que para comprender las intenciones de los personajes es necesario un cierto desarrollo metacognitivo y no un mayor grado de habilidad lingüística. La competencia textual y mediática implica otros procesos metacognitivos como la reflexión sobre el propio proceso de comprensión y producción en referencia a los distintos elementos textuales que lo condicionan. Por otro lado, el dominio de los distintos elementos textuales, el reconocimiento de los factores contextuales, culturales, históricos y socio-económicos permiten el enriquecimiento del texto $\mathrm{y}$ de su transferencia a otros formatos. Esta competencia implica también el dominio de herramientas que posibiliten un tratamiento y una aproximación autónoma al texto como diccionarios, fuentes bibliográficas e internet y también reflexionar sobre la validez y veracidad de estas (KMK 2014: 20-21; Burwitz-Melzer y Caspari, 2017: 62-66).

Hacer esta competencia operativa permite al profesorado formular objetivos precisos con diferentes textos (López Ferrero y Martín Peris, 2013), un mejor diagnóstico de las 
necesidades del alumnado (Burwitz-Melzer y Caspari, 2017: 62-66) así como evaluar la producción y comprensión textual con criterios adecuados, entre otras.

\section{Modelo bidimensional de la competencia textual}

En nuestro departamento hemos sistematizado la competencia textual y mediática en un modelo bidimensional que incluye la competencia que el alumnado debe dominar y la competencia que el profesorado debe poseer para potenciar esta competencia en su grupo. Como se muestra en la figura 2, este modelo implica una serie de subcompetencias necesarias en ambas dimensiones. Una de ellas, la competencia mediática funcional es común por lo que solo se explica en la dimensión del alumnado.

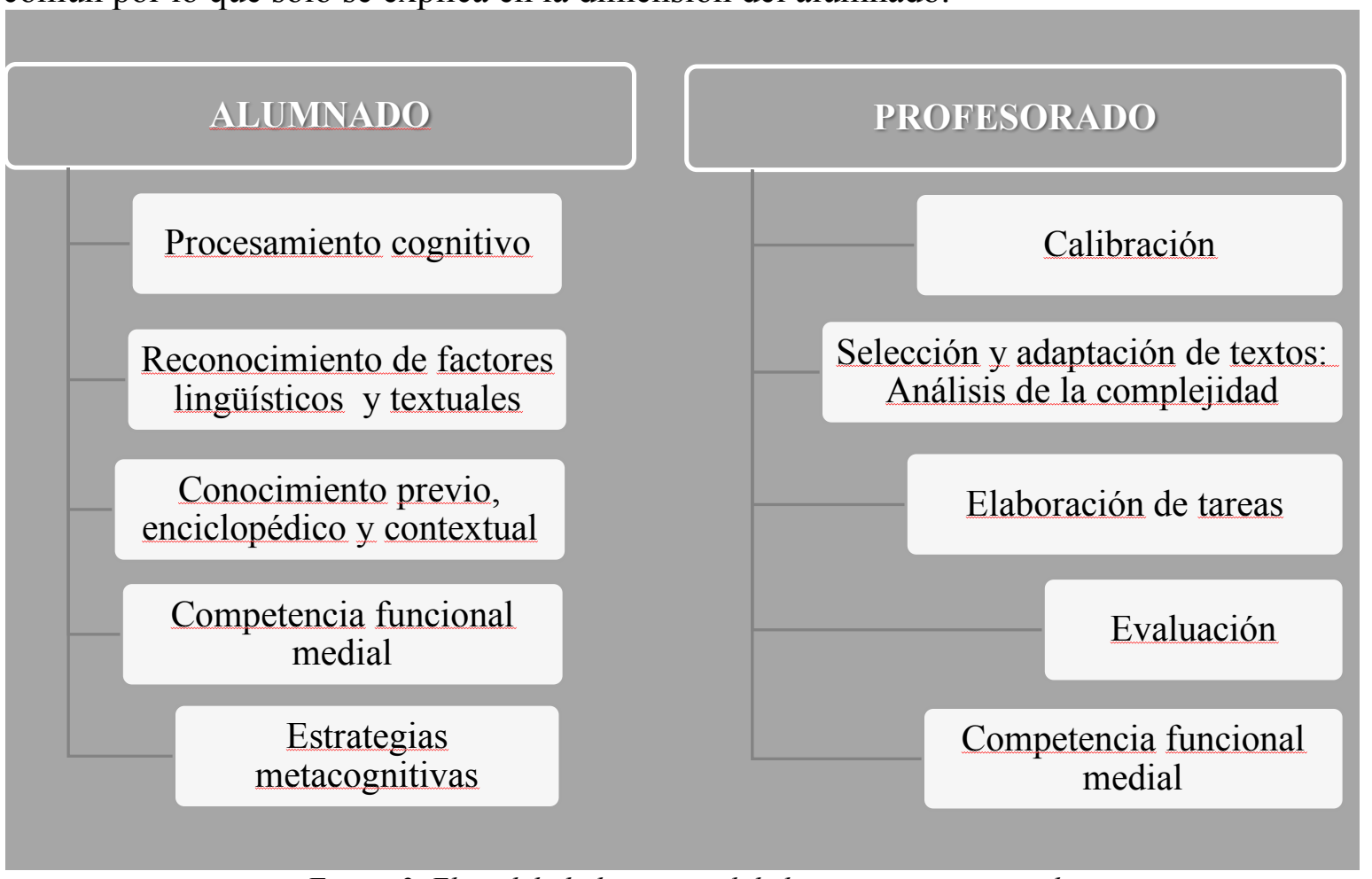

Figura 2. El modelo bidimensional de la competencia textual

\subsection{La competencia textual en el alumnado}

Como observamos en la figura anterior, cuando el alumnado se enfrenta a un texto de cualquier tipo necesita disponer de varios tipos de conocimientos declarativos, procedimentales y actitudinales que sintetizamos a continuación:

- Procesamiento cognitivo. Básicamente se trata de la integración entre lenguaje y pensamiento y hace referencia a los distintos operadores a los que el alumnado debe enfrentarse a la hora de resolver una actividad o tarea (p. ej. analizar, interpretar, justificar, comparar, transformar, valorar, resumir, explicar, etc.). Es fundamental asegurarnos de que el alumnado conoce esos operadores. Por ejemplo, podemos trabajar la producción de resúmenes mediante actividades de identificación de 
palabras clave, de ideas principales, de omisión de información no relevante y de condensación de información relevante.

- Reconocer factores lingüísticos y textuales. El alumnado debe transferir sus conocimientos sobre el marco comunicativo y la micro y macroestructura textual a los diferentes textos que produce o recibe (Janíková \& Reitbrecht 2014: 83). Debe reconocer, analizar y valorar quién lo produce y con qué intención, a quién va dirigido, en qué formato... Debe examinar la macroestructura textual o coherencia global que incluye cuestiones tales como el tipo y formato de texto, tema(s) que en él se exponen así como los elementos paratextuales. Por último, debe ser capaz de analizar y seguir la microestructura o coherencia local que incluye el tipo de léxico empleado (argot, neologismos, arcaísmos, tecnicismos, metáforas, unidades fraseológicas...) y su estructura morfosintáctica. Para ello, obviamente, necesita cierto grado de competencia lingüístico-funcional.

- Conocimiento previo, enciclopédico y contextual. Es imposible que el texto brinde toda la información necesaria para ser interpretado. El autor del texto cuenta con que el receptor posee un cierto conocimiento previo que le guía en el proceso de comprensión del mismo. En este proceso, la información nueva modifica o completa el conocimiento previo (enciclopédico, sobre el mundo, contextual e histórico). Por tanto, la activación del conocimiento previo del alumnado es de vital importancia cuando este se enfrenta a un texto. Aquí se incluyen, por ejemplo, tanto las típicas actividades de prelectura como la elaboración de inferencias a partir del título o de las imágenes. Otra metodología muy interesante empleada por Fisher, Frey y Lapp (2009) es la lectura con la estrategia pensar en voz alta (en inglés, think aloud) en la que el docente hace de modelo al verbalizar las reflexiones sobre su conocimiento previo y las inferencias que realiza mientras lee.

- Competencia funcional mediática. El alumnado debe poseer cierto manejo de dispositivos (p.ej. tabletas, móviles, ordenadores, e-readers, cámaras, grabadoras...) si desea acceder, comprender o producir textos en diferentes formatos. Relacionado muy estrechamente con lo anterior necesita de cierto el dominio en el manejo de programas y aplicaciones ( $\mathrm{p}$. ej. procesadores de texto, editores de imagen, vídeo y audio, etc.). Otras cuestiones como las estrategias de navegación en internet y las relativas a la seguridad en la navegación, la identidad digital, los derechos de los materiales que se encuentran en internet, la eficacia de la búsqueda, la bondad de los materiales, la capacidad crítica a la hora de seleccionar materiales también forman parte de esta subcompetencia.

- Estrategias metacognitivas. La metacognición ${ }^{4}$ implica el conocimiento de la propia actividad cognitiva y el control que la persona tiene sobre dicha actividad. Brown

${ }^{4}$ Flavell (1976: 232) acuña el concepto de metacognición como

[...] conocimiento de uno mismo respecto de los propios procesos cognitivos y sus productos o a cualquier cosa relacionada con ellos, por ejemplo, las propiedades de la información o los datos relevantes para el aprendizaje [...] Metacognición se refiere, entre otras cosas, al control activo y a la consecuente regulación y orquestación de estos procesos en relación con los objetos de conocimiento a los que se refieren, normalmente al servicio de alguna meta concreta u objetivo. 
(1978) afirma que se trata de mecanismos autorregulatorios durante la resolución de tareas. Por tanto, la metacognición conlleva: identificar y definir el problema, planificar y secuenciar la tarea antes de enfrentarse a ella, ser consciente de las propias limitaciones, conocer las estrategias disponibles (p. ej. subrayar, volver a leer, ignorar...), usarlas de manera eficaz y supervisar la eficacia del proceso.

\subsection{El modelo de competencia textual didáctica en el profesorado}

Para promover la competencia textual y mediática en el aula, el profesorado necesita haber adquirido, además de competencias didácticas generales, ciertas subcompetencias específicas que resumimos a continuación.

- Calibración. El profesorado debe adecuar las posibilidades de explotación didáctica de los textos y sus objetivos didácticos a las características de su grupo según su edad, nivel, sus gustos, sus capacidades, su conocimiento previo, sus experiencias con otras lenguas extranjeras, su competencia en lengua materna y por supuesto sus habilidades lingüísticas. Para realizar esta calibración encontramos en el caso de ELE dos documentos básicos. Por un lado, el MCER y por el otro el Plan curricular del Instituto Cervantes (PCIC) o documento donde, entre otros, se especifican y describen los niveles de referencia para el español del MCER. En el caso de educación reglada pueden existir otros documentos normativos que nos faciliten esta calibración ${ }^{5}$.

- La selección de textos y su adaptación. El análisis de la complejidad textual o estimación de la complejidad es una competencia fundamental en el profesorado puesto que va a condicionar decisiones didácticas relevantes en cuanto al tipo y formato de texto adecuado para su grupo. Esta subcompetencia posibilita la anticipación de las dificultades que el alumnado pueda tener con las estructuras lingüísticas (gramaticales, léxicas y estilísticas). Además de la complejidad lingüística, el profesorado debe anticipar otro tipo de dificultades motivadas por el conocimiento previo del alumnado tales como el contexto socio-cultural e histórico en el que se sitúa el texto. Teniendo estos factores en cuenta, podrá elegir el texto más adecuado a sus fines e incluso adaptarlo, simplificándolo o enriqueciéndolo, según los grupos o las características de las personas que conforman el grupo. Las estrategias de simplificación (o enriquecimiento) tienen en cuenta (entre otros) las dificultades características de las lenguas, la cronología de presentación de contenidos lingüísticos en los manuales, MCER y PCIC, las frecuencias relativas de léxico, fenómenos y estructuras en la lengua así como el análisis semántico a través de instrumentos como el TexSem de Gardt (2012).

- La elaboración de tareas. Tanto si se trabaja con manual o no, es necesario saber diseñar o adaptar tareas didácticas eficaces para guiar los procesos de recepción y producción. A la hora de elaborar tareas sobre competencia textual y mediática es

\footnotetext{
${ }^{5}$ En nuestro caso, para calibrar el alumnado de la enseñanza reglada en la secundaria en Alemania contamos con otros dos documentos básicos: los Estándares educativos (Bildungsstandards) a nivel estatal y, su concreción federal o los contenidos mínimos establecidos en el plan de estudios federal (Kerncurricula).
} 
necesario incluir el mayor tipo de textos posible tanto en la recepción como en la producción. Debemos elegir cuidadosamente las fuentes utilizadas puesto que la calidad de los textos modelo depende de la competencia textual de sus autores. La meta de las tareas ha de ser clara y las distintas actividades deben contribuir al andamiaje de esta y del plan curricular que se siga. Las distintas actividades deben estar formuladas de forma precisa y favorecer la cooperación entre el alumnado. Los operadores que utilicemos en ellas (p.ej. resume, reflexiona, valora, compara...) deben ser comprendidos y dominados por el alumnado ${ }^{6}$. Entre los operadores más productivos en tareas de competencia textual se encuentran: resumir, estructurar, analizar, interpretar, reflexionar, valorar, argumentar, buscar información dentro y fuera del texto, ponerse en la piel de los personajes, etc. En general, una buena tarea es aquella en la que se potencia la autonomía del alumnado, se tiene la oportunidad de reflexionar sobre el propio proceso de aprendizaje y el proceso de evaluación y es transparente y útil (Schmölzer-Eibinger, 2011:171).

- La evaluación es un constructo complejo que implica procesos distintos. Por mencionar dos de ellos, nos encontramos con el monitoreo, supervisión o feedback del proceso de producción o recepción ya sea por parte del docente, por parte del alumnado (evaluación entre pares) o autoevaluación. Y, por otro lado, la valoración que implica el establecimiento de criterios de puntuación, esto es, qué y cuándo vamos a valorar o corregir ( $p$. ej. léxico, morfosintaxis, ortografía o adecuación textual, coherencia y cohesión). La selección de estos criterios ha de ser transparente para el alumnado.

\section{Tipos de tareas para promover la competencia textual}

Pasamos ahora a la presentación de una tarea ${ }^{7}$ que implica distintos tipos y formatos textuales. Consiste en meterse en la piel del director o directora de un cortometraje y realizar una entrevista. Esta tarea sigue el modelo didáctico de competencia textual de Schmölzer-Eibinger (2009) e implica tres fases distintas y así como diversas operaciones cognitivas:

a. Fase de activación del conocimiento previo y generación de inferencias acerca de los diálogos, de la atmósfera, de la acción, de los personajes (personalidad, motivaciones...). Reproducimos el corto sin sonido para recoger las primeras impresiones Tras anotarlas, intercambiamos ideas con una pareja. Después, a través de una actividad V/F (o un cuestionario) y su puesta en común, nos aseguramos la comprensión detallada del corto y la reflexión de las respuestas por parte de todo el grupo y, si es necesaria, también la revisión de las mismas.

b. Fase de trabajo con textos. Consiste en seleccionar, enfocar, abstraer y relacionar para construir o reconstruir textos y por último su expansión. Para comenzar

\footnotetext{
${ }^{6}$ Muchas veces tendemos a pensar que el alumnado sabe p.ej. resumir o la diferencia entre comparar y argumentar pero este no es siempre el caso y debemos asegurarnos que comprenden estos operadores antes de que realicen la actividad.

${ }^{7}$ Basada en una tarea de Burwitz-Melzer y Caspari (2017).
} 
realizamos un puzle con las escenas del corto que el grupo debe ordenar. Después, en grupo, se reflexiona sobre los elementos mediáticos utilizados en cada una de ellas (p. ej. sonido, planos, velocidad, colores, símbolos...). A continuación realizamos un dictogloss ${ }^{8}$ con la escena final. Tras esta actividad, cada grupo modifica esa escena para crear su final alternativo justificándolo y reflexionando sobre el uso de los distintos elementos mediáticos necesarios.

c. Fase de transformación de texto o transferencia de información a otro tipo y/o formato textual. En esta fase realizaremos una entrevista con el director de la película. Para ello comenzamos con la preparación y justificación de las preguntas teniendo en cuenta el contexto de la entrevista (p. ej. programa de humor, festival de cine...). Continuamos con su puesta en escena y terminamos la actividad con su publicación en una revista especializada tras una fase de corrección y maquetación de la entrevista.

\begin{tabular}{|c|c|}
\hline FASE & ACTIVIDADES \\
\hline $\begin{array}{l}\text { Activa } \\
\text { conocir }\end{array}$ & $\begin{array}{l}\text { 1. Visionado de un corto sin sonido: anotación de las } \\
\text { primeras impresiones e intercambio de ideas } \\
\text { 2. Visionado con sonido: comprensión del corto (p. ej. } \\
\text { actividad V/F) y puesta en común }\end{array}$ \\
\hline $\begin{array}{l}\text { Trabajo con textos: } \\
\text { - Construcción } \\
\text { - } \text { Reconstrucción } \\
\text { - Enfoque y } \\
\text { expansión }\end{array}$ & $\begin{array}{l}\text { 3. Puzle de escenas } \\
\text { 4. Análisis de los elementos mediáticos utilizados } \\
\text { 5. Dictogloss de la escena final } \\
\text { 6. Imaginar un final justificándolo con los elementos } \\
\text { mediáticos necesarios. }\end{array}$ \\
\hline $\begin{array}{c}\text { Transformación de } \\
\text { Textos }\end{array}$ & $\begin{array}{l}\text { 5. Preparación y justificación de la entrevista } \\
\text { 6. Puesta en escena } \\
\text { 7. Publicación de la entrevista: corrección y maquetación }\end{array}$ \\
\hline
\end{tabular}

\section{Conclusión}

La competencia textual y mediática es básica en esta sociedad en la que a diario recibimos y producimos una gran variedad de textos. Esta competencia implica el conocimiento declarativo, procedimental y actitudinal en cuanto a las condiciones en las que la información es codificada y procesada en los distintos tipos de textos así como sus reglas y características lingüísticas específicas.El profesorado de ELE debería plantearse cuestiones acerca de si los diversos tipos y formatos textuales están representados en el aula. Una de sus metas didácticas ha de ser, entonces, la inclusión de los nuevos productos comunicativos, así como de los medios donde estos aparecen. Esto implica enfrentar al alumnado de lenguas extranjeras no solo a libros, artículos o entradas de la Wikipedia sino también a mapas de metro, youtubers, y redes sociales y el tratamiento de la relación entre esos textos (intertextualidad e intermedialidad). Esta inclusión de nuevos textos implica la priorización del uso de realia en el aula, del aprendizaje en red y de la reflexión sobre la

\footnotetext{
${ }^{8}$ Esta actividad consiste en la reconstrucción de un texto a partir de las notas que se han tomado durante la exposición del mismo. La técnica se atribuye a Ruth Wajnryb (1990).
} 
propia cultura y las otras teniendo en cuenta el papel de variables emocionales y personales (Burwitz-Melzer y Caspari 2017: 59).

\section{Referencias}

BurWITZ-MElzER, E. (2007). «Ein Lesekompetenzmodell für den fremdsprachlichen Literaturunterricht». En L. Bredella y W. Hallet (eds.); Literaturunterricht, Kompetenzen und Bildung (pp. 127-157). Trier: Wissenschaftlicher Verlag.

Burwitz-Melzer, E. y CAspari, D. (2017). «Text- und Medienkompetenz». En: B. Tesch, X. von Hammerstein, P. Stanat y H. Rossa (eds.); Bildungsstandards aktuell: Englisch/Französisch in der Sekundarstufe II (pp. 56-83). Braunschweig: Diesterweg.

CONSEJO DE EUROPA (2001 [2002]). Marco común de referencia para las lenguas: aprendizaje, enseñanza y evaluación. Madrid: Secretaría General Técnica del MECD y Grupo Anaya.

Delors, J. (1996). La educación encierra un tesoro. Madrid: Santillana

Cullen, C. (1996). «El debate epistemológico de fin de siglo y su incidencia en la determinación de las competencias científico tecnológicas en los diferentes niveles de la educación formal». Novedades Educativas, 62, 20-23.

FISHER, D., FREY, N., y LAPP, D. (2009). In a reading state of mind brain research, teacher modeling, and comprehension instruction. Newark, Del.: Internat. Reading Assoc.

GARDT, A. (2012): «Textsemantik. Methoden der Bedeutungserschließung». En Jochen A. Bär/Marcus Müller (Ed.), Geschichte der Sprache und Sprache der Geschichte. Probleme und Perspektiven der historischen Sprachwissenschaft des Deutschen (pp. 61-82). Berlin: Akademie-Verlag.

ISENBERG, H. (1976). «Einige Grundbegriffe für eine linguistische Texttheorie». En F. Danes y D. Viehweger (eds.), Probleme der Textgrammatik. Studia grammatica XI (pp. 47145). Berlin: Akademieverlag.

Islas CARMONA, J. O. (2008). «El prosumidor. El actor comunicativo de la sociedad de la ubicuidad». Palabra clave, 11(1).

JANíkOVÁ, V. y ReITBRecht, S. (2014): «Textkompetenz in mehreren Sprachen». Studia Germanistica, 15, 73-88.

KULTUSMINISTERKONFERENZ (2014). Bildungsstandards für die fortgeführte Fremdsprache (Englisch und Französisch) für die Allgemeine Hochschulreife: (Beschluss der KMK vom 18.10.2012), Köln.

López Ferrero, C. y MARTín Peris, E. (2013). Textos y aprendizaje de lenguas: elementos de lingüistica textual para profesores de ELE. Madrid: SGEL.

OCDE (2005). Definición y Selección de Competencias Clave. Resumen Ejecutivo. Paris: Autor. Recuperado de http://www.deseco.admin.ch/bfs/deseco/en/index/03/02.html. 
OCDE (2000). La medida de los conocimientos y destrezas de los alumnos. Un nuevo marco de evaluación. Madrid: INCE. Recuperado de http://www.oecd.org/education/school/programmeforinternationalstudentassessmentpisa/33 694020.pdf.

Portmann-Tselikas, P. R. (2005). Was ist Textkompetenz? Recuperado de https://www.google.de/search?q=portmann-tselikas\&ie=utf-8\&oe $=$ utf-8\&gws_rd=c r\&ei=nYqwVurNIsX2Ov_8rOAM.

SCHMÖLZER-EIBINGER, S. (2011). Lernen in der Zweitsprache. Grundlagen und Verfahren der Förderung von Textkompetenz in mehrsprachigen Klassen. Tübingen: Narr.

SCHMÖLzER-EIBINGER, S. (2009). «Ein 3-Phasen-Modell zur Förderung der Textkompetenz». Fremdsprache Deutsch. (39), 28-33.

Vygotsky, L. S. (1989). El desarrollo de los procesos psicológicos superiores. Barcelona: Crítica.

WAJNRYB, R. (1990). Grammar dictation. Oxford: Oxford University Press 